\title{
PENERAPAN MODEL PEMBELAJARAN \\ COOPERATIF INTEGRATED READING AND COMPOSITION (CIRC) DENGAN MIND MAPPING TERHADAP KEMAMPUAN BERPIKIR KRITIS SISWA KELAS XI IPA SMAN 1 BOJONGSOANG PADA MATERI SISTEM EKSKRESI
}

\author{
Meti Maspupah ${ }^{1}$, Ara Hidayat ${ }^{2}$, dan Rosiana Latifah ${ }^{3}$ \\ ${ }^{123}$ Pendidikan Biologi, MIPA, Universitas Islam Negeri Bandung \\ metimaspupah@uinsgd.ac.id
}

\begin{abstract}
Abstrack The low ability of students to ask questions, express idea and record well and quickly make the students less focus on the material presented by the teacher. This situation lead the researchers to apply Cooperative Integrated learning model Reading and Composition (CIRC) with Mind Mapping. The objectives of this study is to describe the learning process of teachers and students as well as to analyze students' critical thinking skills by using Cooperative Integrated Reading And Composition (CIRC) model with Mind Mapping on grade XI IPA SMAN 1 Bojongsoang. This research used Pre-Experiment method with One Group Pretest-Posttest design. Analysis of research data include normality test, $t$-test or wilcoxon test. The results showed that RPP validation is very feasible to be used in learning with percentage of $91.3 \%$, and the implementation of teacher and student learning is very good. Wilcoxon test showed that Cooperative Integrated Reading And Composition (CIRC) learning model with Mind Mapping can give positive contribution to students' critical thinking ability on excretory system material.
\end{abstract}

Keywords: Critical thinking ability, Learning model, CIRC with Mind Mapping

Abstrak. Rendahnya kemampuan siswa dalam bertanya dan mengungkapkan ide serta gagasan, rendahnya kemampuan siswa untuk mencatat baik dan cepat membuat siswa kurang memusatkan perhatian pada materi yang disampaikan oleh guru, serta belum terimplementasinya model-model pembelajaran yang ada, membuat peneliti tertarik untuk menerapkan model pembelajaran Cooperative Integrated Reading And Composition (CIRC) dengan Mind Mapping. Penelitian ini bertujuan untuk mendeskripsikan proses pembelajaran guru dan siswa serta menganalisis kemampuan berpikir kritis siswa dengan menggunakan model Cooperative Integrated Reading And Composition (CIRC) dengan Mind Mapping pada kelas XI IPA SMAN 1 Bojongsoang. Penelitian ini menggunakan metode Pre-Eksperimen dengan desain One Group Pretest-Posttest. Analisis data penelitian meliputi uji normalitas, uji-t atau uji wilcoxon. Hasil penelitian menunjukkan hasil validasi RPP sangat layak untuk digunakan dalam pembelajaran dengan presentase sebesar 91,3\%, serta keterlaksanaan pembelajaran guru dan siswa sangat baik dengan Hasil kemampuan berpikir kritis siswa yang mencapai KKM memiliki presentase 14,87\% pada kelas XI IPA 2 dan 39,20\% pada kelas XI IPA3. Hasil Uji Wilcoxon menyatakan bahwa model pembelajaran Cooperative Integrated Reading And Composition (CIRC) dengan Mind Mapping dapat memberikan kontribusi positif terhadap kemampuan berpikir kritis siswa pada materi sistem ekskresi.

Kata Kunci : Kemampuan berpikir kritis, Model pembelajaran, CIRC dengan Mind Mapping, Keterlaksanaan pembelajaran guru dan siswa, Sistem Ekskresi 


\section{PENDAHULUAN}

Berdasarkan studi pendahuluan yang telah dilakukan oleh peneliti di SMA Negeri I Bojongsoang melalui wawancara dengan guru biologi kelas XI, terdapat permasalahan yang ditemukan dalam pembelajaran biologi khususnya dalam materi sistem ekskresi, diantaranya yaitu

kebanyakan siswa kurang mampu mengembangkan kemampuan berpikir kritis sesuai dengan tuntutan kurikulum. Hal ini jelas terlihat dari hasil pembelajaran sebelumnya, ditandai dengan rendahnya kemampuan siswa dalam bertanya, kurangnya kemampuan untuk mengungkapkan ide atau gagasan yang dimiliki serta pemahaman konsep pada siswa membutuhkan waktu yang cukup lama, sementara waktu yang disediakan terbatas. Terlebih, kurangnya kemampuan siswa dalam mencatat dengan baik dan cepat, membuat siswa kurang memusatkan perhatian pada materi yang disampaikan oleh guru, serta belum terimplementasinya model-model pembelajaran yang dapat meningkatkan kemampuan berpikir kritis.

Materi sistem ekskresi dipilih karena dianggap mempunyai tingkat kesukaran yang cukup tinggi terlihat dari konsep, proses, gejala dan peristiwa yang berkaitan didalamnya. Materi ini akan sulit dipahami jika disampaikan dengan metode konvensional saja, sehingga untuk membangun kemampuan berpikir kritis dibutuhkan model dan metode yang dapat memotivasi peserta didik agar lebih mengerti, sehingga tidak mudah dilupakan setelah pembelajaran materi ini selesai.

Biologi merupakan bagian dari IPA yang mempelajari permasalahan yang berkaitan dengan fenomena alam dan berbagai permasalahan yang terkait dengan penerapannya untuk membangun teknologi guna mengatasi permasalahan dalam kehidupan masyarakat.

Hal ini sejalan dengan pernyataan Hidayat (2011:7) bahwa Proses pembelajaran IPA yang menitikberatkan pada suatu proses penelitian atau eksperimen, maka sangat diharapkan dalam proses belajarnya mampu meningkatkan proses berpikir peserta didik untuk memahami fenomenafenomena alam. Selain itu, diharapkan juga dapat membangkitkan minat manusia, IPA juga memberikan kemampuan dalam mengembangkan ilmu pengetahuan dan teknologi serta pemahaman tentang alam semesta yang mempunyai banyak fakta yang belum terungkap dan masih bersifat rahasia, sehingga hasil penemuannya dikembangkan menjadi ilmu pengetahuan alam yang baru dan dapat diterapkan dalam kehidupan sehari-hari.

Berdasarkan latar belakang diatas, salah satu model pembelajaran yang tepat agar siswa dapat mengembangkan kemampuan berpikir kritis yang optimal yaitu model pembelajaran Cooperative integrated Reading And Composition (CIRC) yang dipadukan dengan Mind Mapping yang diterapkan pada materi sistem ekskresi.

Berpikir kritis sangat penting dalam mempelajari biologi karena berpikir kritis mencakup seluruh proses mendapatkan, membandingkan, menganalisis, mengevaluasi, dan bertindak melampaui ilmu pengetahuan dan nilai- nilai. Dalam pembelajaran biologi kemampuan berpikir kritis siswa sangat berperan dalam prestasi belajar, penalaran formal, keberhasilan belajar, dan kreatifitas karena berpikir merupakan inti pengatur tindakan siswa.

Komara (2014:7) yang menyatakan agar siswa dapat berhasil ketika proses belajar, diperlukan persyaratan tertentu 


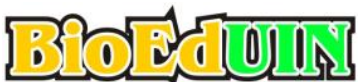

Jurnal Program Studi Pendidikan Biologi

antara lain kemampuan berpikir yang tinggi bagi para siswa, hal ini ditandai dengan berpikir kritis, logis, sistematis dan objektif. Belajar bukanlah suatu hasil, akan tetapi merupakan proses untuk mencapai tujuan dalam rangka memenuhi kebutuhan menuntut ilmu.

Kemampuan berpikir kritis ini sesuai seperti halnya dengan pernyataan Sudiarta (2009) bahwa kemampuan berpikir kritis adalah kegiatan kognitif yang dilakukan siswa dengan cara membagi-bagi cara berpikir dalam kegiatan nyata dengan memfokuskan pada membuat keputusan mengenai apa yang diyakini dan dilakukan.

Mengembangkan kemampuan berpikir kritis siswa dapat dilakukan dengan pelatihan. Salah satunya dengan memberikan tugas terstruktur untuk membuat Mind Mapping sebelum pembelajaran. Ini dilakukan untuk menanamkan konsep dan pemahaman konsep biologi yang diharapkan memberi kemudahan bagi siswa untuk memahami materi yang di ajarkan.

Hal ini sejalan dengan penelitian yang dilakukan oleh Wahyuningsih, dkk. (2011 menyatakan bahwa strategi pembelajaran aktif Mind Maps memberikan kemudahan bagi siswa untuk lebih mudah dalam memahami dan mengingat materi yang diberikan oleh guru.

Penggunaan peta pikiran (Mind Mapping) akan mampu meningkatkan kemampuan berpikir kritis siswa, karena dibuat sendiri oleh siswa, dibangun berdasarkan alur berpikir siswa. Hal ini akan memberikan hasil berupa bentuk peta pikiran yang berbeda antara masing-masing siswa (Listyawati).
p-ISSN : 2338-7173

e-ISSN : 2615-0417

(Februari), Vol. (8), No.(1)

Model pembelajaran Cooperative Integrated Reading And Composition (CIRC) merupakan model pembelajaran terpadu menggabungkan kemampuan menulis dan membaca sehingga diharapkan dapat melatih siswa untuk bekerjasama dan memberikan tanggapan dan pendapat secara bebas (Heriawan, 2012:116). Hal ini sejalan dengan penelitian yang dilakukan oleh Jatmiko et.al (2013) merupakan program pengajaran khusus yang dirancang untuk meningkatkan kinerja siswa dalam membaca dan menulis. Sehingga siswa mampu mengeluarkan ide-ide untuk memahami suatu konsep dan menyelesaikan tugas, sehingga membentuk pemahaman dan pengalaman belajar yang lama.

Berdasarkan penjelasan di atas, peneliti tertarik menerapkan Model Pembelajaran Cooperative Integrated Reading And Composition(CIRC) yang dipadukan dengan Mind Mapping. Penelitian ini merupakan pengembangan dari penelitian sebelumnya yang menitikberatkan pada hasil belajar yang dilakukan oleh Marpuah, dkk (2013) dapat meningkatkan hasil belajar siswa pada materi invertebrata di kelas X SMA, karena dengan menggunakan model pembelajaran yang dikombinasikan ini dapat mengarahkan siswa untuk lebih mudah memahami materi dalam pembelajaran, sehingga siswa dapat melakukan kegiatan membaca dan menulis secara keseluruhan dan siswa menjadi lebih efektif, kreatif dan kritis ketika membaca.

\section{METODE PENELITIAN}

Penelitian ini dilakukan di SMAN 1 Bojongsoang Kab. Bandung. Penelitian dilaksanakan pada semester genap tahun 2016/2017. Populasi penelitian ini adalah seluruh kelas XI IPA (1, 2, dan 3). Sampel penelitian ini ditentukan secara Purposive Sampling, yaitu kelas 


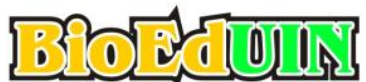

Jurnal Program Studi Pendidikan Biologi
p-ISSN : 2338-7173

e-ISSN : 2615-0417

(Februari), Vol. (8), No.(1)
XI IPA 2 sebagai kelas eksperimen 1 dan kelas XI IPA 3 sebagai kelas eksperimen 2. Penelitian ini merupakan penelitian pre-eksperimen dengan desain One Group Pretest-Posttest. Variabel bebas dalam penelitian ini adalah CIRC dengan Mind Mapping pada materi sistem ekskresi, sedangkan variabel terikat berupa hasil kemampuan berpikir kritis siswa. Data penelitian ini berupa data PretestPosttest, keterlaksanaan aktivitas siswa dan guru. Data hasil kemampuan berpikir kritis dianalisis dengan menggunakan uji normalitas, uji $\mathrm{t}$ (untuk data yang normal), dan uji wilcoxon (untuk data yang tidak normal).

\section{HASIL DAN PEMBAHASAN}

\section{Lembar Validasi RPP}

Sebelum menerapkan model pembelajaran Cooperative Integrated Reaading And Composition (CIRC) dengan Mind Mapping ada proses perencanaan yang harus dipersiapkan dengan matang yaitu dengan penyusunan RPP.

Menurut Trianto (2007) RPP merupakan panduan guru dalam melakukan kegiatan pembelajaran yang dituangkan dalam skenario kegiatan. RPP yang akan digunakan dalam pembelajaran harus valid dan dinyatakan layak sehingga diharapkan dapat membuat siswa lebih terarah dalam melakukan kegiatan. Hal ini sesuai dengan pernyataan yang dikeluarkan oleh Depdiknas (2008) bahwa perencanaan pembelajaran hendaknya dikembangkan dengan menyesuaikan kebutuhan dan karakteristik sekolah, siswa, mata pelajaran, dan lain-lain. Apabila perencanaan pembelajaran telah dilakukan dengan matang, maka guru dan siswa akan lebih mudah dan terarah dalam melaksanakan pembelajaran. RPP dikatakan layak, jika sudah memenuhi semua aspek yang dituangkan dalam lembar validasi. Adapun hasil analisis validasi RPP dapat dilihat pada tabel 4.3 berikut:

Tabel 4.3 Analisis Validasi Rencana Pelaksanaan Pembelajaran

\begin{tabular}{|c|l|c|}
\hline No & \multicolumn{1}{|c|}{ Aspek yang Dinilai } & $\begin{array}{c}\text { Rata- } \\
\text { Rata } \\
\text { Skor }\end{array}$ \\
\hline 1. & Identitas Mata Pelajaran & 5 \\
\hline 2. & Perumusan Indikator & 5 \\
\hline 3. & $\begin{array}{l}\text { Perumusan Tujuan } \\
\text { Pembelajaran }\end{array}$ & 5 \\
\hline 4. & Pemilihan Materi Ajar & 5 \\
\hline 5. & Pemilihan Sumber Belajar & 4 \\
\hline 6. & Metode Pembelajaran & 4 \\
\hline 7. & Skenario Pembelajaran & 5 \\
\hline 8. & Rancangan Penilaian Autentik & 4 \\
\hline 9. & Bahasa & 4 \\
\hline 10. & Waktu & 4 \\
\hline
\end{tabular}

Adapun rekapitulasi data validasi perangkat pembelajaran dapat dilihat pada tabel 4.4 berikut:

Tabel 4.4 Rekapitulasi Data Validasi Perangkat Pembelajaran

\begin{tabular}{|c|c|c|}
\hline RPP & $\begin{array}{c}\text { Rata-rata } \\
\text { Skor }(\boldsymbol{\%})\end{array}$ & Kategori \\
\hline Validator & $91,3 \%$ & Sangat Layak \\
\hline
\end{tabular}

Berdasarkan tabel 4.4 di atas menunjukkan bahwa perangkat pembelajaran berupa RPP dinyatakan sangat layak dan dapat digunakan untuk penelitian, karena memenuhi aspekaspek yang baik dan harus ada di dalam rencana pembelajaran. Hal ini sesuai dengan pernyataan Menurut Khoiriyah, dkk (2014) menyatakan Rencana Pelaksanaan Pembelajaran (RPP) dan Lembar Kerja Siswa (LKS) merupakan salahsatu perangkat pembelajaran sebagai wujud persiapan yang dilakukan oleh guru sebelum mereka 


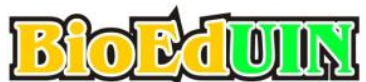

Jurnal Program Studi Pendidikan Biologi

melakukan proses pembelajaran. Untuk membuat perencanaan yang baik dan dapat menyelenggarakan proses pembelajaran yang ideal, setiap guru harus mengetahui unsur-unsur perencanaan yang baik.

\section{Lembar Observasi}

\section{Keterlaksanaan Guru dan Siswa}

Keterlaksanaan penerapan Model Pembelajaran Cooperative Integrated Reading And Composition (CIRC) dengan Mind Mapping pada materi sistem ekskresi dapat diketahui dari hasil lembar observasi. Lembar observasi ini terdiri dari lembar observasi keterlaksanaan guru dan siswa. Data observasi diperoleh melalui pengamatan langsung dengan cara mencatat dan mendokumentasikan pada saat prose pembelajaran berlangsung dengan menggunakan teknik checklist.

Presentase rata-rata keterlaksanaan aktivitas Pembelajaran guru pada kelas ekskperimen 1 dapat digambarkan dalam grafik 4.6 berikut:

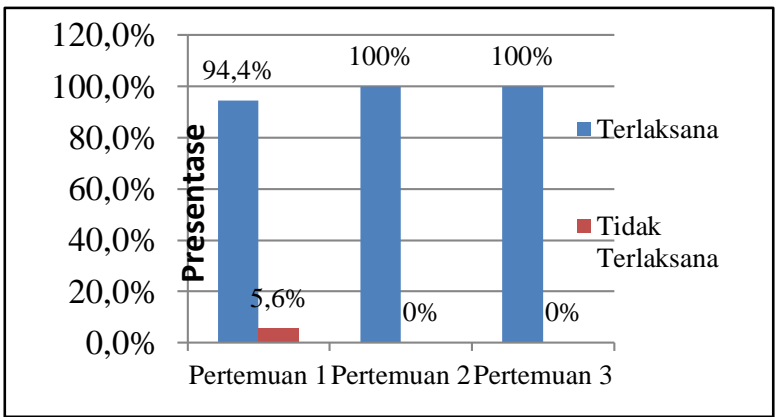

Gambar 4.6 Grafik Rekapitulasi Hasil Observasi Aktivitas Pembelajaran Guru di Kelas Eksperimen 1

Presentase rata-rata keterlaksanaan aktivitas Pembelajaran guru pada kelas ekskperimen 2 dapat dijelaskan dalam Gambar 4.8. Adapun presentase keterlaksanaan pembelajaran siswa di kelas eksperimen 1 dapat dijelaskan dalam Gambar 4.9 dan presentase keterlaksanaan pembelajaran siswa di
p-ISSN : 2338-7173

e-ISSN : 2615-0417

(Februari), Vol. (8), No.(1)

kelas eksperimen 2 dapat dijelaskan dalam Gambar 4.10 berikut ini.

Berdasarkan Gambar 4.6 dan 4.8 menunjukkan hasil keterlaksanaan aktivitas guru terlaksana dengan presentase rata- rata

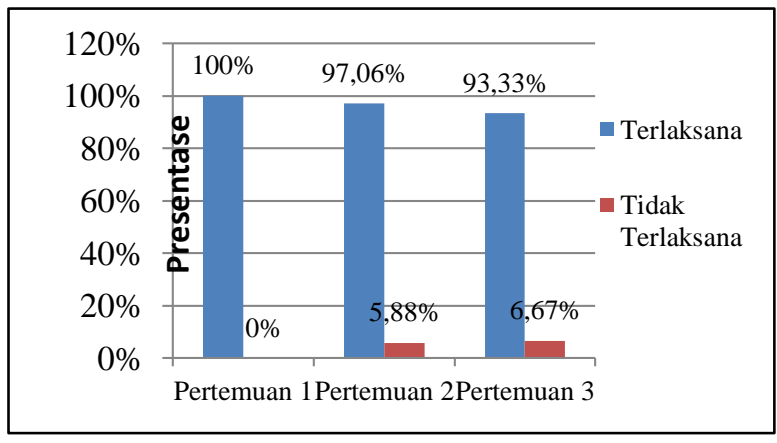

Gambar 4.8 Grafik Rekapitulasi Hasil Observasi Aktivitas Pembelajaran Guru di Kelas Eksperimen 2

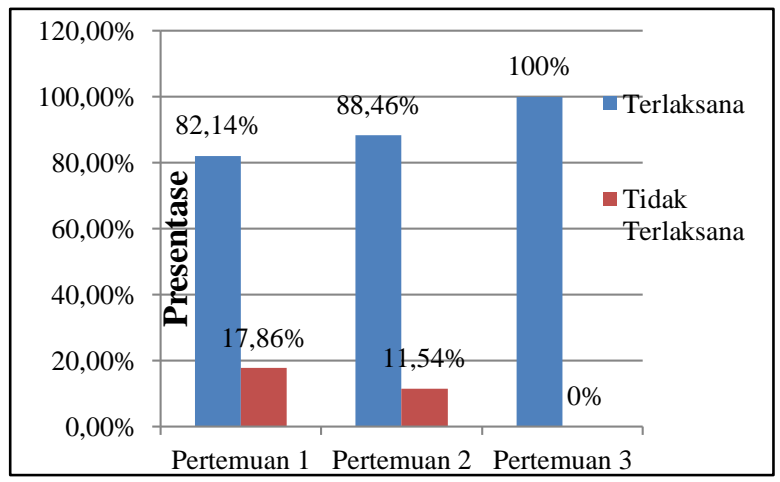

Gambar 4.9 Grafik Analisis Hasil Observasi Aktivitas Pembelajaran Siswa Kelas Eksperimen 1

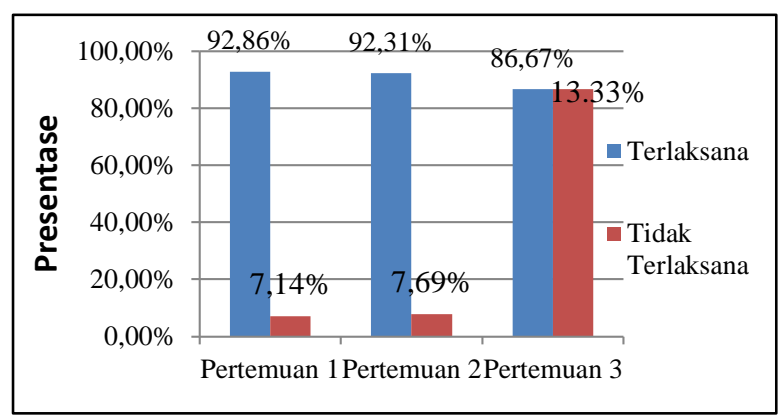

Gambar 4.10 Grafik Analisis Hasil Observasi Aktivitas Pembelajaran Siswa Kelas Eksperimen 2 


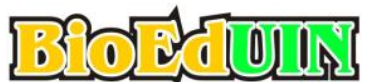

Jurnal Program Studi Pendidikan Biologi
p-ISSN : 2338-7173

e-ISSN : 2615-0417

(Februari), Vol. (8), No.(1)
98,13\% pada kelas eksperimen 1(XI IPA 2) dan 95,82\% pada kelas eksperimen 2 (XI IPA 3). Sedangkan berdasarkan grafik 4.9 dan 4.10 menunjukkan hasil keterlaksanaan aktivitas siswa terlaksana dengan sangat baik dengan presentase rata-rata 90,20\% pada kelas eksperimen 1 (XI IPA 2) dan 90,61\% pada kelas eksperimen 2 (XI IPA 3).

\section{Hasil Kemampuan Berpikir Kritis Siswa}

Hasil kemampuan berpikir kritis kelas eksperimen 1 secara keseluruhan dengan menggunakan model pembelajaran Cooperative Integrated Reading And Composition (CIRC) dan Mind Mapping dapat dilihat pada tabel 4.18 berikut:

Tabel. 4.18 Rekapitulasi Hasil Kemampuan Berpikir Kritis Siswa Kelas Eksperimen 1

\begin{tabular}{|c|c|c|c|c|c|}
\hline Data & $\begin{array}{c}\Sigma \\
\text { Siswa }\end{array}$ & Skor & $\begin{array}{c}\text { Rata } \\
\text {-rata }\end{array}$ & $\%$ & Ket. \\
\hline \multicolumn{6}{|c|}{ Pretest } \\
\hline $\begin{array}{c}\Sigma \\
\text { Siswa }\end{array}$ & 0 & 0 & 0 & $0 \%$ & $\begin{array}{c}\geq \\
\text { KKM }\end{array}$ \\
\cline { 2 - 6 } & 31 & 1440 & 46,45 & $100 \%$ & $\begin{array}{c}< \\
\text { KKM }\end{array}$ \\
\hline Total & 31 & 1440 & - & $100 \%$ & - \\
\hline & \multicolumn{5}{|c|}{ Posttest } \\
\hline $\begin{array}{c}\Sigma \\
\text { Siswa }\end{array}$ & 3 & 239 & 79,67 & $14,87 \%$ & $\begin{array}{c}\geq \\
\text { KKM }\end{array}$ \\
\cline { 2 - 6 } & 28 & 1368 & 48,85 & $85,13 \%$ & $\begin{array}{c}< \\
\text { KKM }\end{array}$ \\
\hline Total & 31 & 1607 & - & $100 \%$ & - \\
\hline
\end{tabular}

Adapun rekapitulasi hasil kemampuan berpikir kritis siswa kelas eksperimen 2 secara ringkas dengan menggunakan model pembelajaran Cooperative Integrated Reading And Composition (CIRC) dan Mind Mapping dapat dilihat pada tabel 4.19 berikut:

Tabel 4.19 Rekapitulasi Hasil Kemampuan Berpikir Kritis Siswa Kelas Eksperimen 2

\begin{tabular}{|c|c|c|c|c|c|}
\hline Data & $\begin{array}{c}\Sigma \\
\text { Siswa }\end{array}$ & $\begin{array}{c}\text { Total } \\
\text { Skor }\end{array}$ & $\begin{array}{c}\text { Rata- } \\
\text { rata }\end{array}$ & $\%$ & Ket. \\
\hline \multicolumn{6}{|c|}{ Pretest } \\
\hline E Siswa & 2 & 160 & 80 & $9,35 \%$ & $\begin{array}{c}\geq \\
\text { KKM }\end{array}$ \\
\cline { 2 - 6 } & 30 & 1552 & 51,37 & $\begin{array}{c}90,65 \\
\%\end{array}$ & $\begin{array}{c}< \\
\text { KKM }\end{array}$ \\
\hline
\end{tabular}

\begin{tabular}{|c|c|c|c|c|c|}
\hline Total & 32 & 1712 & & $100 \%$ & \\
\hline \multicolumn{6}{|c|}{ Posttest } \\
\hline \multirow{2}{*}{$\Sigma$ Siswa } & 10 & 839 & 83,90 & $\begin{array}{c}39,20 \\
\%\end{array}$ & $\begin{array}{c}\geq \\
\text { KKM }\end{array}$ \\
\cline { 2 - 6 } & 22 & 1309 & 59,50 & $60,80 \%$ & $\begin{array}{c}< \\
\text { KKM }\end{array}$ \\
\hline Total & 32 & 2140 & & $100 \%$ & \\
\hline
\end{tabular}

Berdasarkan tabel 4.18 menunjukan bahwa hasil kemampuan berpikir kritis siswa dengan menggunakan model pembelajaran Cooperative Integrated Reading And Composition (CIRC) dan Mind Mapping masih dikategorikan sangat rendah dengan presentase $14,87 \%$ bagi siswa yang sudah mencapai atau lebih dari KKM dengan rata-rata nilai sebesar 79,67 dan 85,13\% bagi siswa yang belum mencapai KKM. Walaupun demikian, hasil tersebut telah mengalami peningkatan dari data hasil kemampuan berpikir kritis sebelumnya yang menunjukkan siswa sama sekali belum ada yang mencapai KKM.

Berdasarkan tabel 4.19 menunjukan bahwa hasil kemampuan berpikir kritis siswa dengan menggunakan model pembelajaran Cooperative Integrated Reading And Composition (CIRC) dan Mind Mapping masih dikategorikan cukup dengan presentase 39,20\% bagi siswa yang sudah mencapai atau lebih dari KKM dengan rata-rata nilai sebesar 83,90 dan $60,80 \%$ bagi siswa yang belum mencapai KKM. Hal ini menunjukkan peningkatan yang cukup signifikan dibandingkan data sebelumnya, presentase siswa yang mencapai KKM sebesar 9,35\%.

Kemampuan berpikir kritis yang masih dikategorikan jauh dari ekspektasi ini, dikarenakan dalam proses pembelajaran siswa masih belum terbiasa untuk membuat Mind Mapping. Siswa terbiasa belajar dengan menggunakan metode diskusi dan ceramah serta model pembelajaran lainnya yang dapat meningkatkan prestasi belajar seperti 


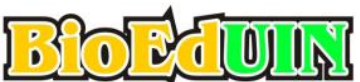

Jurnal Program Studi Pendidikan Biologi
p-ISSN : 2338-7173

e-ISSN : 2615-0417

(Februari), Vol. (8), No.(1) inquiry, dan discovery learning. Sehingga, ketika siswa diberikan pembelajaran dengan Mind Mapping siswa lebih terpusat dengan bagaimana membuat Mind Mapping yang baik yang menghubungkan warna, simbol, gambar, garis dan kata dari pada memahami peta pemikiran materi. Hal ini sesuai dengan Kurniawati (2009) yang menyatakan bahwa kelemahan Strategi Mind Maps adalah siswa tidak sepenuhnya belajar.

Hasil pembuatan Mind Mapping pada kelas eksperimen 1 dan kelas eskperimen 2 menunjukkan bahwa siswa yang dapat mencapai KKM hanya memiliki presentase sebesar 25,06\% dan $23,35 \%$. Presentase ini terbilang masih rendah, sehingga mempengaruhi hasil kemampuan berpikir kritis yang rendah juga. Walaupun demikian, siswa tetap mengalami peningkatan kemampuan berpikir kritis, hal ini sejalan dengan penelitian yang dilakukan oleh Ristiasari (2012:37) yang menujukkan kemampuan berpikir kritis siswa pada kelas eksperimen mengalami peningkatan karena pemberian tugas Mind Mapping.

Data hasil penelitian dianalisis dengan menggunakan uji normalitas terlebih dahulu. Kemudian dilakukan uji-t jika data hasil uji normalitas berdistribusi normal. Jika data yang dihasilkan tidak berdistribusi normal maka dilakukan uji statistik nonparamterik dengan menggunakan uji wilcoxon. Berdasarkan perhitungan kelas eksperimen 1 dengan menggunakan uji wilcoxon menunjukkan bahwa $Z_{\text {hitung }}$ $(2,78)>Z_{\text {tabel }}(-1,96)$ maka Ho ditolak artinya Penerapan Model Cooperative Integrated Reading And Composition (CIRC) dan Mind Mapping dapat memberikan kontribusi yang positif terhadap kemampuan berpikir kritis siswa pada materi sistem ekskresi. Sedangkan perhitungan data pada kelas eksperimen 2 menggunakan uji-t menunjukkan bahwa diperoleh $t_{\text {hitung }} \geq$ $\mathrm{t}_{\text {tabel }}=4,73 \geq 2,04$, maka Ho ditolak artinya Penerapan Model Pembelajaran Cooperative Integrated Reading And Composition (CIRC) dan Mind Mapping dapat memberikan kontribusi yang positif terhadap kemampuan berpikir kritis siswa pada materi sistem ekskresi.

\section{KESIMPULAN}

Berdasarkan hasil penelitian dan pembahasan mengenai penerapan model pembelajaran Cooperative Integrated Reading And Composition (CIRC) dan Mind Mapping pada materi sistem ekskresi, maka dapat diambil kesimpulan sebagai berikut:

1. Proses penerapan model pembelajaran Cooperative Integrated Reading And Composition (CIRC) dan Mind Mapping pada materi sistem ekskresi di kelas XI IPA SMAN 1 Bojongsoang melalui validasi keabsahan perangkat pembelajaran berupa RPP dikategorikan sangat layak dengan presentase 91,3\%.

2. Keterlaksanaan aktivitas guru dan siswa dengan penerapan model pembelajaran Cooperative Integrated Reading And Composition (CIRC) dan Mind Mapping pada materi sistem ekskresi di kelas XI IPA 2 sebagai kelas eksperimen 1 memperoleh rata-rata sebesar 98,13\% dan 90,20\% dengan kategori sangat baik. Sedangkan Keterlaksanaan aktivitas guru dan siswa dengan penerapan model pembelajaran Cooperative Integrated Reading And Composition (CIRC) dan Mind Mapping pada materi sistem ekskresi di kelas XI IPA 3 


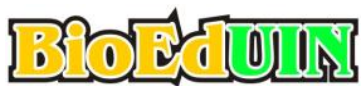

Jurnal Program Studi Pendidikan Biologi

sebagai kelas eksperimen 2 memperoleh rata-rata sebesar 95,82\% dan 90,61\% dengan kategori sangat baik.

3. Hasil kemampuan berpikir kritis siswa dengan menerapkan model pembelajaran Cooperative Integrated Reading And Composition (CIRC) dan Mind Mapping pada materi sistem ekskresi di kelas XI IPA 2 memiliki presentase sebesar 14,87\% dengan rata-rata 79,67 dan XI IPA 3 memiliki presentase sebesar $39,20 \%$ dengan rata-rata 83,90 dengan kategori cukup karena mengalami peningkatan dari $0 \%$ pada kelas eksperimen 1 dan $29,85 \%$ pada kelas eksperimen 2. Berdasarkan data di atas, dapat disimpulkan bahwa penerapan model pembelajaran Cooperative Integrated Reading And Composition (CIRC) dan Mind Mapping dapat memberikan kontribusi positif terhadap kemampuan berpikir kritis siswa pada materi sistem ekskresi.

\section{DAFTAR PUSTAKA}

Departemen Pendidikan Nasional

(Depdiknas). 2008. Panduan

Penyusunan RPP. Jakarta:

Departemen Pendidikan

Nasional, Dirjen Manajemen

Pendidikan Dasar dan

Menengah, Direktorat Pembinaan

Sekolah Menengah Atas.

Kurniawati, Dhida. 2010.

Pengaruh Metode Mind Mapping

Dan Keaktifan Belajar Siswa

Terhadap Prestasi Belajar Ilmu

Pengetahuan Sosial Pada Siswa

Kelas VIII Sekolah Menengah

Pertama Muhammadiyah 5

Surakarta Tahun Pelajaran

2009/2010. Skripsi. Surakarta:

Universitas Muhammadiyah

Surakarta
p-ISSN : 2338-7173

e-ISSN : 2615-0417

(Februari), Vol. (8), No.(1)

Heriawan, Adang. 2012. Metodologi

Pembelajaran Kajian Teoritis

Praktis. Banten: LP3G

Hidayat, Ara \& Imam. 2011. Pengelolaan Pendidikan.

Bandung: Pustaka Educa

Jatmiko A, Maridi \& J Ariyanto.

2013. Penerapan Model

Pembelajaran

Kooperatif Tipe CIRC

(Cooperative Integrated Reading

And Composition) Disertai Media

Komik Biologi Untuk

Meningkatkan Minat Belajar

Siswa Dalam Pelajaran Biologi

Pada Siswa Kelas VII-A SMP

Negeri 14 Surakarta Tahun

Pelajaran 2011/2012. Vol. 1,

No.5 hal 15-25. Jurnal Pendidikan

Biologi FIKP UNS. Tersedia di:

http://biologi.fkip.uns.ac.id/wp-

content/uploads/2012/02/JURNA

L-PENDIDIKAN-

BIOLOGI_AGUNG-

J_K4308023.pdf (Di akses

tanggal, 02 Januari 2017, 09:13)

Khoiriyah, dkk. 2014.

Pengembangan

Rencana Pelaksanaan

Pembelajaran dan Lembar Kerja

Siswa Model Pembelajaran Core

dengan Teknik Mind Mapping

Pokok Bahasan Bangun Ruang

Sisi Lengkung Kelas IX SMP. Vol.

5, No. 3, hal 137-146. Desember

2014 (Diakses Jum'at

04-08-2017)

Komara, E. 2014. Belajar dan

Pembelajaran

Interaktif.

Bandung: Refika Aditama

Listyawati,Ni Wyn dkk. -. Pengaruh

Model Pembelajaran Kuantum Berbantuan Peta Pikiran terhadap Kemampuan Berpikir Kritis Siswa Pada Pembelajaran IPA Kelas $V$ SD. Universitas Pendidikan Ganesha, Singaraja Indonesia 
Marpuah, dkk. 2015. Efektivitas

Model

Pembelajaran Cooperative

Integrated Reading and

Composition (CIRC) dengan

Mind Mapping. Vol. 3, No. 4 hal 34-41 Semarang: Jurusan Biologi, FMIPA Unnes. Tersedia di:

http://lib.unnes.ac.id/21252/ (Di akses tanggal 02 Januari 2017, 09:22)

Sudiarta, 2009. Pengembangan

pembelajaran berpendekatan tematik berorientasi pemecahan masalah matematika terbuka untuk mengembangkan kompetensi berpikir divergen, kritis, dan kreatif. Jurnal Pendidikan dan Pengajaran. Vol 2. No.4:373-39

Ristiasari, T. 2012. Model

Pembelajaran Problem Solving Dengan Mind Mapping

Terhadap Kemampuan Berpikir Kritis Siswa. Unnes Journal of Biology Education. Vol. 1, No 3 hal 34-41.

Trianto. 2007. Model Pembelajaran

Terpadu dalam Praktik dan teori. Jakarta: Prestasi Pustaka

Wahyuningsih, Danik. 2011.

Pengaruh

Strategi Pembelajaran Aktif Mind Maps Terhadap Hasil Belajar Biologi Siswa Kelas XI IPA SMA Negeri 2 Karanganyar. Jurnal Pendidikan Biologi. Vol.3, No. 2. 